\section{DISIDENTES Y VISIONARIAS DE LOS NUEVOS FEMINISMOS}

\author{
Cristina Abad Cadenas \\ Periodista \\ crisabad@yahoo.es
}

\begin{abstract}
Cómo citar este artículo/Citation: Abad Cadenas, C. (2016). "Disidentes y visionarias de los nuevos feminismos". Arbor, 192 (778): a308. doi: http://dx.doi.org/10.3989/
\end{abstract} arbor.2016.778n2011

Recibido: 08 septiembre 2015. Aceptado: 14 septiembre 2015.

RESUMEN: Desde el siglo XIX hasta hoy son innegables los cambios generados por el feminismo de la primera, segunda y tercera ola. Aficionados a conceptualizar y etiquetar, actualmente enfilamos la entrada a la cuarta ola, una ideología menos monolítica, más fragmentaria y plural que, según Elena Gascón-Vera, profesora en Wellesley College, combina feminismo, lucha por los derechos queer y otros movimientos pro-sex. Un movimiento, según la periodista británica Kira Cochrane, centrado en las pequeñas causas concretas que basa sus reivindicaciones en las herramientas digitales. Merece la pena valorar si se trata de un avance o un desarrollo de la indeterminación postmoderna apoyada por la tecnología 3.0. En todo caso, la Utopía Feminista ha dejado también cadáveres en el camino que no siempre asumimos y reconocemos o si lo hacemos es como precio a pagar. Muchas veces las víctimas son las propias mujeres. La política y escritora italiana Eugenia Roccella considera que las utopías se han desplazado de lo social a la biología y dejan a la mujer ante la encrucijada de deconstruir lo materno y la diferencia sexual o defender a ultranza esa diferencia. Eveyne Sullerot, socióloga feminista francesa, lamenta la fragilidad dramática que se ha instalado en la sociedad, por la frecuencia de las separaciones y la deriva del aborto que al grito de "mi vientre es mío" vacían de sentido la paternidad. El feminismo tal y como se concibe no es la puerta del paraíso. Todavía queda mucho camino que recorrer. Se atisba una necesidad de desarrollar la vertiente ecológica. La crisis y las dificultades familiares de estos primeros años del siglo XXI han supuesto un buen desafío para muchas de las feministas de los años 60 y 70 . Algunas, como las citadas o las estadounidenses Christina Hoff Somersson, Eugenia Roccella, Karen DeCrow o Camille Paglia, han revisado sus mensajes. En este artículo comentaremos las aportaciones de estas disidentes o visionarias.

PALABRAS CLAVE: Nuevos feminismos; postfeminismo; mujer; cuarta ola; disidentes.

\section{DISSIDENTS AND VISIONARY WOMEN OF THE NEW FEMINISMS}

Copyright: (C) 2016 CSIC. Este es un artículo de acceso abierto distribuido bajo los términos de la licencia Creative Commons Attribution (CC BY) España 3.0.

ABSTRACT: The world has experienced undeniable changes provoked by the first, second and third wave feminisms from the nineteenth century. We are used to conceptualizing and labeling everything, and nowadays we are facing the fourth wave, a less compact, more fragmented and plural ideology that, as Elena Gascón-Vera (Professor at Wellsley College) explains, combines feminism and fights for the rights of queer and other pro-sex movements. The fourth wave, according to the British journalist Kira Cochrane, is focused on small more specific causes, and supports its claims on digital tools. It would be very interesting to assess whether this is a breakthrough or just the development of postmodern uncertainty supported by 3.0. technology. In any case, Feminist Utopia has led society to errors that are often not acknowledged and, if they are, they are justified as a price to pay. In many cases, the victims are the women themselves. The Italian politician and writer Eugenia Roccella considers that utopias have moved from social conflict to mere biology, making women choose between destroying both maternity and sexual difference, or defending these differences at all costs. Eveyne Sullerot, a French feminist sociologist, regrets the dramatic fragility established in society, as a consequence of frequent breakups and abortion, justified by the cry of "my belly is mine", which take the meaning out of parenthood. Feminism, as it is conceived, is not the panacea. We still have a long road ahead. We can glimpse a need to develop the ecologic trend. The recession and family difficulties of the first years of the 21st Century have become a challenge for many feminists from the 60s and 70s. Some of them, such as the above or the American Christina Hoff Somersson, Eugenia Roccella, Karen DeKrow or Camille Paglia, have already started to reword their messages. In this article we discuss the contributions of these dissident or visionary women.

KEYWORDS: New feminisms; postfeminism; women; fourth wave; dissidents. 
Los cambios generados por la marea feminista en la sociedad contemporánea son innegables. La primera ola del siglo XIX nos trajo el sufragio de las mujeres; la segunda, en los años 60 del siglo XX, la liberación sexual; y la tercera, en los 90, la sustitución de sexo por género y su consideración como un constructo cultural elegible y manipulable a voluntad por la ciencia y la tecnología.

Hoy las mujeres, al menos en el mundo occidental, ven reconocidos muchos derechos fundamentales y tienen acceso a la educación, a la cultura, a la vida política y social, al mercado laboral, si no en igualdad de condiciones con los hombres en todos los aspectos, casi a la par. Al mismo tiempo, la búsqueda de la utopía feminista ha dejado cadáveres en el camino que no siempre asumimos y reconocemos, o si lo hacemos es como precio a pagar por la "libertad" adquirida.

Paradójicamente, esas víctimas son, en ocasiones, las propias mujeres obligadas a elegir entre profesión o maternidad por exigencias económicas y ambientales. La dificultad para conciliar familia y trabajo, el incremento de la infertilidad como consecuencia del uso continuado de métodos anticonceptivos y de ritmos de vida estresantes, la banalización de la sexualidad donde la prostitución o el abuso cobran carta de naturaleza, la violencia doméstica, la soledad ante el drama del aborto y sus secuelas psicológicas, son algunas de las heridas del llamado Primer Mundo.

\section{CUARTO FEMINISMO, NUEVOS FEMINISMOS, POST- FEMINISMO}

Aficionados a conceptualizar y etiquetar, hemos enfilado la cuarta ola del feminismo en el siglo XXI, con una ideología "menos monolítica, más fragmentaria y plural que, combina feminismo, lucha por los derechos queer y otros movimientos pro-sex", como describe Carolina Moloni, investigadora y profesora de la Universidad Europea de Madrid. Un movimiento "centrado en las pequeñas causas concretas que apoya sus reivindicaciones en las herramientas digitales", según la periodista británica Kira Cochrane. "La fragmentación implica pluralidad", concluye June Fernández, directora de Pikara Magazine. Y en ella caben "todo tipo de corrientes que abordan temas muy diversos desde enfoques variopintos, ecofeminismo, transfeminismo, economía feminista, feminismo cristiano, feminismo islámico, feminismo gitano" (Yanke, 2015, 8 de marzo).

Muchos optan por no denominar el fenómeno en singular, sino en plural: "nuevos feminismos". O, atendiendo a una visión temporal, "post-feminismo", como lo llama Beatriz Preciado: no exactamente como algo superado sino como "un proceso de revisión, crítica y reconstrucción de las categorías con las que trabajábamos hasta ahora". Para ello, Preciado plantea "nuevas articulaciones entre cuerpo, poder y placer que escapen a las estructuras normativas de género y sexualidad" (Precht, 2008, 19 de marzo).

Iniciamos este siglo con la caída de las torres gemelas y otros atentados del terrorismo islámico. La aparición de movimientos reactivos como la Marcha Verde, la Primavera Islámica y el 15-M, que saludamos con entusiasmo en su momento, hoy nos deja con la duda de si no habrán contribuido a retroalimentar el radicalismo en Oriente y a expandir su acción a Occidente. A esto hay que añadir la crisis económica mundial y el surgimiento de nuevos gigantes económicos, etc. El inestable equilibrio de potencias ha sido alterado y no sabemos a dónde nos dirige.

En el campo que nos ocupa, la evolución del feminismo, la incertidumbre y la confusión alcanzan cotas de paradoja: la teoría del cyborg, de Donna Haraway, ese organismo cibernético, cuerpo híbrido que ya no tiene una identidad masculina o femenina, sino múltiple, producto del "bricolaje", convive con el ecologismo; los métodos artificiales de fecundación, considerados la encarnación de la libertad sexual, con la defensa de los métodos naturales de fertilidad, que ha dado lugar a la "pullout generation", como la llama Ann Friedman en un artículo de The Cut. O con movimientos internacionales como "Stop subrogación Now", contrario al alquiler de vientres, al que recientemente se han sumado en España filósofas, constitucionalistas y feministas con una campaña para frenar la regularización de la maternidad subrogada: "no somos vasijas humanas" -dicen-; movimientos radicales como FEMEN o \#WomenAgainstFeminism (WAF) que, bajo ese hashtag, expresa su rechazo al feminismo de la segunda y tercera ola.

¿Podemos hablar con propiedad de una cuarta ola o este galimatías es más bien el desarrollo de la indeterminación postmoderna apoyada y propiciada por la tecnología 3.0, como inmensa Torre de Babel?

\section{CUESTIÓN DE COMUNICACIÓN}

Según Asunción Bernárdez Rodal, directora del Instituto de Investigaciones Feministas de la Universidad Complutense de Madrid, "el cambio más espectacular que ha vivido el feminismo entre 2000 y 2015 es el de las formas de comunicación". "Internet está 
democratizando el acceso al feminismo" (...). "Ahora somos las más jóvenes las que usamos nuestros blogs como pancartas", asegura con entusiasmo Carmen G. de la Cueva, periodista, poeta y editora del portal sobre feminismo y literatura "La tribu de Frida" (Yanke, 2015, 8 de marzo).

Quizá sea nada más y nada menos que eso, y la poderosa maquinaria de la comunicación se encarga de dar más protagonismo al feminismo radical y a todo este cúmulo de fragmentarias reivindicaciones; pero las consecuencias existenciales de aquellas políticas prometedoras de los primeros feminismos han acabado por desencantar a muchas de las feministas de los años 60 y 70 como Christina Hoff Sommers, Eugenia Roccella, Karen DeCrow o Camille Paglia, que han revisado sus mensajes y procuran alzar su voz.

Este artículo, más periodístico que de investigación, pretende dar eco a algunas de estas voces disidentes y ofrecer su visión de los caminos que deberían tomar los nuevos feminismos para responder a las necesidades y aspiraciones de las mujeres del siglo XXI.

\section{LA VERDAD DE LA “GUERRA” CONTRA LAS MUJERES}

Manuel Ruiz Zamora, historiador del arte y filósofo, recoge en un artículo publicado en el diario El País el malestar que empieza a detectarse en algunos foros progresistas ante la intolerancia del feminismo radical, definido por su "sectarismo", una de cuyas manifestaciones es silenciar a los discrepantes y considerarlos parte de la conspiración (Ruiz Zamora, 2010, 1 de marzo).

Ya hace un par de años, en un artículo publicado en Public discourse, se recogían datos de encuestas que desmienten el dogma feminista radical de que todas las mujeres se consideran víctimas de una "guerra" contra ellas. Según la teoría difundida sobre todo por el lobby pro-choice, esta agresión se manifiesta de forma reductiva en los límites impuestos a los derechos en materia de "salud reproductiva", y en especial al aborto.Los datos que aporta ese artículo matizan bastante esta "verdad absoluta" proclamada y asumida en la opinión pública. Al parecer no todas las mujeres tienen una opinión unitaria en estos temas y tampoco son estos los únicos que les preocupan:

Según una encuesta reciente (agosto) de ámbito nacional, un $60 \%$ de ellas [las mujeres norteamericanas] consideran que el aborto debería ser legal siempre o en la mayoría de los casos, frente al 53\% de los hombres.
Otra pregunta de la misma encuesta revela que un $60 \%$ de las encuestadas serían partidarias de rebajar el límite para la legalidad del aborto a las 20 semanas, en lugar de las 24 vigentes; además, un $8 \%$ adicional prohibiría el aborto en cualquier caso. En cambio, los porcentajes para los hombres son del $50 \%$ y el $6 \%$ respectivamente.

Las leyes contra el sufrimiento del feto, que pretenden ilegalizar los abortos realizados una vez el feto tiene el sistema nervioso suficientemente desarrollado para sentir el dolor, se han convertido en otro aspecto del enfrentamiento en el tema del aborto. (...) Lo mismo puede decirse de uno de los últimos caballos de batalla pro-choice en Estados Unidos: que se permita a personal hospitalario no médico -como enfermeras o matronas- realizar abortos. Una ley en este sentido ha sido recientemente aprobada en California. (...) Tampoco puede decirse que la ley responda a la opinión mayoritaria de los californianos: según una encuesta, el $65 \%$ de ellos se opone a la norma, aunque en este caso no se distinguen hombres de mujeres (Kuebler, 2013, 30 de octubre).

Aparte de los llamados "derechos reproductivos", existen amenazas y agresiones reconocidas por las mujeres que no solo no tienen eco en las proclamas feministas radicales sino que en algunos casos han sido propiciadas por el feminismo radical:

En una presentación para la Asociación Americana de Sociología en 2011, la investigadora y profesora Paul England señalaba que la cultura del hookup (relaciones efímeras y sin compromiso emocional que frecuentemente no van más allá de los encuentros sexuales) en los campus norteamericanos está tan marcada por sexos, y es tan lesiva para la mujer, como los antiguos roles femeninos de sumisión contra los que se rebeló el feminismo: muchos estudiantes siguen utilizando a las mujeres como objeto de placer, frecuentemente aprovechándose de la mayor vulnerabilidad sentimental de ellas.

Según un estudio hecho por ella misma entre universitarios de Standford, mientras que solo un $25 \%$ de las chicas no pretendía una relación romántica cuando se "enrolló por última vez", el porcentaje entre los chicos era del $40 \%$. Además, un $55 \%$ de las estudiantes encuestadas decían que se habían sentido menos respetadas por la otra parte después del encuentro sexual. Para England, la cultura del hookup perpetúa en los campus la tradicional dominación del hombre sobre la mujer en materia afectiva y sexual. 
Otra forma de dominación machista, que tampoco parece interesar mucho al lobby feminista, es la presión para abortar que sufren las mujeres. Según un estudio con datos de 2004, un 64\% de las mujeres que abortan en Estados Unidos lo hace bajo alguna forma de presión, casi siempre por parte de su pareja, lo que muchas veces provoca episodios de estrés post-traumático (Kuebler, 2013, 30 de octubre).

Christina Hoff Sommers, escritora y filósofa estadounidense, madre de los términos "feminismo de equidad" y "feminismo de género", y autora de libros críticos contra el feminismo contemporáneo como Who Stole Feminism? y The War Against Boys, fustiga ese "feminismo victimista", que "tiende a ver la masculinidad convencional como una patología y como el origen de muchos de los males del mundo" y denuncia la utilización fraudulenta de encuestas que dan soporte a esa actitud:

Me di cuenta de que la mayoría -no todas- de las estadísticas sobre víctimas eran, en el mejor de los casos, equívocas, y en el peor, completamente inexactas. (...) Para las mujeres que verdaderamente están en riesgo de sufrir violencia o discriminación serían de gran ayuda investigaciones veraces y de calidad. La situación de las mujeres no mejora con política de género y exageraciones, por mejor intencionadas que sean (...). Las afirmaciones falsas, las hipérboles y las alarmas infundadas perjudican la credibilidad y eficacia del feminismo en general. El mundo necesita con urgencia un movimiento feminista ponderado, responsable y basado en la realidad (Hoff Sommers, 2008, 19 de noviembre).

La opinión de Hoff Sommers es compartida por Elisabeth Badinter, profesora de Filosofía en la Escuela Politécnica de París, estudiosa del movimiento feminista, quien mantiene en su ensayo Por mal camino que "hay que luchar para ganar la igualdad con los hombres, no contra ellos". "El varón no es un enemigo a abatir sino un compañero al que implicar en el cambio". Badinter considera que los avances de los años 70 y 80 fueron loables, pero han tropezado con una estructura social rígida (horarios de trabajo, reparto de tareas domésticas...) que impiden la igualdad. El desencanto ha dado paso a un feminismo radical, que coloca a la mujer como víctima de la dominación del hombre y necesitada de la protección especial de las leyes (2004). La crisis económica de estos últimos años ha anquilosado y agravado esta situación.

La crisis ha sido un factor muy regresivo. Ha generado una gran desconfianza respecto al mundo laboral y ha acentuado esa voluntad de repliegue en el hogar. Ante la precariedad imperante y la desigualdad salarial, muchas mujeres prefieren refugiarse en la familia y la descendencia (Vicente, 2015, 18 de agosto).

Una de las consecuencias prácticas de la actitud antimasculina dominante en el feminismo radical es la tendencia a feminizar la enseñanza. La veterana feminista Camille Paglia cree que la corriente dominante dentro del feminismo contemporáneo ha logrado que cale la idea de que los hombres son unos brutos (Weiss, 2013, 28 de diciembre).

Y Christina Hoff Sommersen considera que la escuela está creando "un ambiente tóxico para los niños", a los que se intenta inculcar a toda costa valores femeninos. "La teoría de género que hoy se imparte en la universidad es bastante antimasculina y se limita a neutralizar la masculinidad" (Hoff Sommersen, 2013, 20 de agosto).

\section{LA MUJER FETICHE DEL HOMBRE}

Políticas, sociólogas, filósofas, periodistas, modelos y diseñadoras... Desde todos los ámbitos profesionales surgen voces femeninas que piden que el pensamiento feminista modere su radicalidad y responda a sus necesidades vitales. Muchas de ellas han dedicado años a la teoría feminista o a la práctica, imbuidas en un torbellino laboral absorbente. Ahora no tienen miedo de poner el dedo en la llaga de ese feminismo, que se vuelve contra las mujeres,e invocar que se imponga el sentido común.

El tabú se ha roto, las nuevas tecnologías propician el acceso a ideas distintas, aunque estas sean arrolladas por la mainstream. Merece la pena dejarlas hablar a ellas para conocer de primera mano su visión del feminismo, empezando a ras de suelo, en el ejercicio del ser mujer, profesional y madre, para ahondar cada vez más en las razones que les han llevado a disentir.

Eva Herman, presentadora durante 18 años del informativo más famoso de la televisión pública alemana, divorciada tres veces y con un solo hijo, se planteó por qué Europa estaba llena de mujeres cansadas de perseguir su autorrealización personal. Del análisis surgió un libro, El principio de Eva, que le valió una persecución en toda regla que acabó con su expulsión de la televisión:

La sociedad es incapaz de llamar la atención sobre esta realidad, porque no encaja con el discurso con el que las feministas, en su mayoría solteras, pretendían convencernos hace algunos decenios: todo es 
planificable, nos decían, y, para realizarnos, debemos superar ese vínculo con un marido y un hijo. Digámoslo con toda tranquilidad: nosotras mismas nos cargamos el peso de esas contradicciones a las espaldas, nosotras mismas nos convertimos en el juguete de los ofrecimientos seductores y las promesas de una carrera profesional. Al emprender la batalla por nosotras mismas, por nuestra independencia... y la batalla contra los hombres, pasamos por el aro que nos pusieron delante de las narices en vez de detenernos y plantearnos las auténticas preguntas vitales (Herman, 2008).

En el campo de la moda, la top-model argentina Valeria Mazza, la brasileña Gisele Bundchen, que hace unos meses hizo pública su decisión de abandonar la pasarela, o la española Judit Mascó, son ejemplos de profesionales de primera línea que llegadas a determinada edad decidieron dedicarse a aspectos de su trabajo más compatibles con su deseo de ser madres. Todas están casadas: la primera y la tercera tienen cuatro hijos y la Bundchen, dos. Y se sienten felices ejerciendo la maternidad. En una entrevista Valeria comentó:

Quise tener los cuatro hijos y hoy disfruto de tener esta familia que soñé. El día a día es duro, pesado, hace falta mucha paciencia. Por eso, me hace bien tener mi trabajo: cuando regreso a casa, soy mejor madre y esposa. No tengo esa culpa que embarga a muchas mujeres que también trabajan fuera de casa. Hay que relajarse y disfrutar de lo que una hace en cada momento.

Y Judith Mascó asegura:

Hay etapas en las que das más prioridad a una cosa que a otra. Todo bien no se puede hacer. Mira, en la etapa en la que las niñas eran más pequeñas, que tenía que estar más pendiente de ellas, aminoré el ritmo... Pero nunca he abandonado mi trabajo. Me gusta mucho lo que hago. Quiero hacerlo. He luchado mucho en mi vida para llegar hasta aquí como para dejarlo todo, ¿no? Y ahora que mis hijas son más mayores, dispongo de más tiempo y sí, estoy más activa que nunca (Infante, 2015, 30 de enero).

En otro orden de cosas, pero destacando las contradicciones de la libertad sexual, la diseñadora venezolana Carolina Herrera llamaba la atención recientemente contra el naked dress, la moda de llevar vestidos que dejan el cuerpo prácticamente desnudo:

Se supone que son íconos de moda y no llevan puesto nada. Esto se ha convertido en una obsesión (...). Piensan que es muy moderno ir desnudo, o casi desnudo. Creen que con estos vestidos van a llamar la atención de los jóvenes, pero la respuesta es ino! En la vida tiene que haber algo de misterio (...). Para mí, la moda es originalidad, sofisticación y belleza. Yo no soy parte del negocio de la moda, soy parte del mundo de la belleza (Givhan, 2015, 8 de junio).

Otro ejemplo elocuente nos lo aporta la periodista Natasha Walter, impulsora del nuevo feminismo, que en su libro Muñecas vivientes arremete contra la esclavización de la imagen que viven muchas niñas desde pequeñas. Walter entrevistó a jóvenes, empresarios y trabajadores del sector del porno soft y explica en su reportaje lo que ocurre cada noche en determinados locales de Londres que pasan por simples discotecas. Allí muchas chicas, no siempre de estratos económicos y culturales desfavorecidos, prueban fortuna como "modelos", convencidas de que la exposición de su cuerpo como objeto sexual es el máximo ideal feminista:

Hombres y mujeres siguen sin encontrarse en igualdad de condiciones en la vida pública. Y la normalización de la industria del sexo refleja esa desigualdad. Son las mujeres las que hacen dietas draconianas y someten sus cuerpos a la cirugía, son las mujeres las que se desnudan en las discotecas mientras los hombres las jalean y aplauden; son las mujeres, y no los hombres, quienes piensan que su capacidad para acceder a la fama y al éxito depende de lo bien que respondan a una única y reducida imagen de la sexualidad. Si esta es la nueva liberación sexual, se parece demasiado al viejo sexismo como para convencernos de que se trata de la libertad a la que aspirábamos (Walter, 2010).

Desde el Instituto de Bioética Southern Cross en Adelaida (Australia), Zac Alstin, Ilega al fondo del problema con un reportaje publicado en MercatorNet.com que lleva por título La defensa de los niños contra la cultura erotizada de los adultos. En él advierte sobre la preocupación de instancias como la American Psychological Association, un comité del Senado de Australia o el Ministerio del Interior británico con respecto a la sexualización de las niñas, que relacionan con problemas de salud mental como trastornos alimentarios, baja autoestima y depresión. El corazón del problema, según Alstin, es que los niños -personas cultural, física y mentalmente demasiado jóvenes como para participar en la cultura sexual de los adultosse han moldeado y modelado para que coincidan con una cultura de adultos erotizada (Alstin, 2010, 5 de octubre). 
Y hace tan solo unos meses, la psicoanalista Constanza Michelson, denunciaba en un artículo muy osado que levantó ampollas, el dominio masculino del discurso feminista en el terreno sexual. Merece la pena recoger algunos párrafos:

Después de tanta lucha que hemos dado para salir de la opresión de la norma macho, nos tropezamos con algo curioso y sintomático: nos hemos transformado en una fantasía masculina. (...) Así, muchas veces nos convertimos en esa amiga-amigo que declara ser distinta a sus congéneres. $Y$ que se empeña en buscar cuestiones fálicas, como el poder, la competencia (...). Lo que no sería problemático si no fuera porque, en la exaltación de esa vía, renegamos de cosas como la palabra, la cercanía y el cuidado. Todo bajo el nombre de liberación. (...) A veces la libertad prometida no es más que una nueva domesticación.

Nos enseñaron a pensar que el único mecanismo de control social era la represión y que, por lo tanto, librarse de las ataduras significaba libertad. $Y$ es cierto que las mujeres hemos tenido que pelear frontalmente con el poder para lograr cierta justicia y dignidad. Sin embargo, olvidamos que la ideología también se instala a través de discursos y prácticas que parecen neutrales. $Y$ es por esta vía que nos hemos construido una autoimagen que tiene mucho de impostura masculina.(...) Sin darnos cuenta, nos hemos ido construyendo como mujeres hiperdefensoras de lo masculino, dejando a un lado nuestro gran capital transformador: el campo de las relaciones. Ese tejido social que apunta al cuidado y la cooperación.

No se trata de defender las viejas instituciones de lo amoroso, que también nos aplastaban; pero el simulacro del touch and go crónico deshumaniza. Se trivializa el cuerpo, se mecaniza el sexo y se atenta contra las posibilidades de un encuentro: la amistad, la ternura, la solidaridad, al menos una fraternidad política con el otro (Michelson, 2015, 16 de julio).

\section{FEMINISTAS RADICALES DE IDA Y VUELTA}

Eveyne Sullerot, es una socióloga feminista francesa de 89 años, que fue cofundadora de la primera asociación a favor de la planificación familiar en 1956. Recientemente publicó una carta abierta a sus bisnietos, en la que mostraba su perplejidad ante el futuro incierto al que se enfrentaban las nuevas generaciones pese a las luchas por los derechos de la mujer y el progreso económico que dominaron mayo del 68.
En Carta de una hija de la guerra a los hijos de la crisis denuncia el individualismo imperante hoy: "Si en 1997 el 40\% de los nacimientos se producía fuera del matrimonio y de manera voluntaria, en 2006 estos representaban el 50\% y en 2012 el 57\%". Sullerot lamenta que para la izquierda "todo lo que se califica de familiar resulte sospechoso de tradicional". Y concluye: "Para los indiferentes y los herederos de mayo del 68, los sexualistas, los hedonistas anarquizantes, la mayoría de los gays y las hiperfeministas, antes morir que ser tradicional".

A su edad, la veterana feminista tiene energías para proponer un debate nacional para incentivar la natalidad, que desemboque en un plan político que permita al país progresar. $Y$ critica al ultrafeminismo que al grito de "mi vientre es mío", ha elevado el número de abortos legales (en 2011, unos 222.500) y han vaciado de sentido la paternidad dejando fuera del terreno de juego a los varones (Sullerot, 2014).

\section{EL DERECHO A NO TENER QUE ELEGIR}

La historiadora francesa Ivonne Knibiehler, de 84 años y madre de tres hijos, y figura del feminismo, explicaba en una entrevista en Le Monde que "estaba persuadida de que la maternidad seguiría siendo una cuestión capital de la identidad femenina. (...) El feminismo debe en primer lugar repensar la maternidad: todo lo demás le será dado por añadidura". "Desde el principio -dice- no podía contentarme con esa orden implícita: Sé madre y cállate. Intuía que la maternidad era "una función social. Y estaba convencida de que si se acallaba, se ignoraba al menos la mitad de las realidades maternas" (Alonso-Gutiérrez, 2007, 21 de febrero).

Y Harriet Harman, abogada y líder del Partido Laborista británico recomienda a las mujeres británicas "no tener los hijos tan tarde como yo" (tuvo tres entre los 32 y los 37 años), y considera que "la salud y bienestar de madres e hijos, y las elecciones personales, deberían decidir la edad para tener hijos, y no el mercado de trabajo".

La función social a la que alude Knibiehler incluye, además la necesidad del relevo generacional y el sostenimiento del sistema de pensiones. En nuestro país, la reciente encuesta del CIS asegura que el español quiere tener 2,8 hijos, pero solo tiene 1,2. "Estamos haciendo un suicidio demográfico. Hay que crear empleo, tanto como apoyar a las familias para cuidar a los hijos y a los dependientes, y esto pasa por flexibilizar y racionalizar horarios" -recuerda Nuria Chinchilla, profesora del IESE de Barcelona (Blazquez, 2015, 27 de abril). 
A día de hoy la conciliación trabajo-familia sigue siendo una patata caliente, que se pasan gobiernos y empresas. Consuelo León, directora del Observatorio de Políticas Familiares de la Universitat Internacional de Catalunya (UIC) y coautora del libro La ambición femenina. Como re-conciliar trabajo y familia junto a Nuria Chinchilla, reconoce que en España es un espejismo:

No tanto por la ley sino por las empresas, por una mala cultura directiva donde reina el presentismo en vez del trabajo por objetivos. Es necesario que acabemos con esta costumbre pero para ello sería muy deseable que a nivel político se cambiaran horarios de cierres de tiendas, de colegios, informativos... Una serie de medidas que forzaran al mundo laboral a replantearse sus tiempos. Además, la crisis y la precariedad hacen que muchas empresas abusen y sugieran a las madres tomarse permisos maternales más cortos de lo que la ley dispone o a no hacer uso del derecho de jornada reducida .(Abundancia, 2014, 8 de mayo).

En cuanto al reparto de tareas y responsabilidades del hogar, las opiniones son tan múltiples como las circunstancias de las familias. Para Knibiehler, la conciliación no pasa "necesariamente por un reparto igualitario de las tareas parentales", "aunque solo sea porque las mujeres siguen involucrándose más que los padres, y porque reducir los cuidados a los hijos pequeños lo viven como una privación. Será necesario que las jóvenes generaciones lleguen a resolver esta cuadratura del círculo, que hoy día padecen tanto los padres como los hijos".

Inda Schaenen, periodista y profesora se declara Radical Feminist Stay-at-Home Mom (madre ama de casa feminista radical), siente que "las mujeres que se dedican al hogar a tiempo completo con hijos pequeños no tienen voz en la arena pública". Así lo recoge The Mommy Wars un libro en el que una periodista del Washington Post reunió 26 reflexiones de madres de todo tipo con el objeto de buscar una tregua en la supuesta guerra que existe en el mundo anglosajón entre amas de casa y madres que trabajan fuera (Alonso-Gutiérrez, 2007, 21 de febrero).

\section{LA MENTIRA DE LA TECNO MATERNIDAD}

Merece la pena destacar por la agudeza de su visión, a la periodista ypolítica italiana Eugenia RocceIla -diputada en el Parlamento y vicepresidenta de la Comisión de Asuntos Sociales, hija de uno de los fundadores del Partido Radical y de una pintora- fe- minista, que a los 18 años entra en el Movimiento de liberación de la mujer, quien tiene ahora una opinión bastante dispar de la tecnomaternidad como derecho de las mujeres:

Las mujeres se encuentran ante una encrucijada. O seguir la tendencia dominante de la deconstrucción de lo materno y de la diferencia sexual, lo que trae consigo el desmantelamiento de las relaciones fuertes que constituyen el grupo humano y el empobrecimiento del sentido y del carácter sagrado de la vida, o defender incansablemente la diferencia, e intentar frenar la deriva antropológica de nuestras sociedades (...).

Con el siglo XX debería haber terminado la era de las utopías totalitarias. Pero la ciencia, sustituyendo a las perdidas utopías del siglo XX, renueva las ilusiones y espejismos de felicidad terrenal, prometiendo, como ha escrito Enzensberger, "la victoria sobre todas las carencias y sobre todas las dificultades de la especie, sobre la ignorancia, el dolor y la muerte (...).

Han triunfado, política y culturalmente, las dos líneas de pensamiento que esencialmente niegan la realidad del cuerpo sexuado y la centralidad de la maternidad para las mujeres. Para el emancipacionismo, el modelo es el cuerpo masculino, "libre" de la procreación, del embarazo, del parto, en una palabra de la maternidad. La procreación asistida nació, aparentemente, para satisfacer el deseo irrefrenable de tener un hijo. La primera paradoja está en la exaltación del derecho al niño en una sociedad que apenas tiene hijos y a la que la continuidad generacional importa más bien poco (...). La segunda paradoja es que mientras la filiación natural (cuando el padre y la madre, mezclando sus gametos, dan vida a un niño y le transmiten su patrimonio genético propio) es cuestionada, se da la máxima importancia sentimental a la consanguinidad, es decir, al deseo de tener un niño no adoptado. (...).

En definitiva, parece como si volviéramos a la retórica de los instintos y sentimientos del siglo XIX: el hijo carne de mi carne y sangre de mi sangre, aunque en realidad solo lo sea parcialmente. El absoluto natural y el absoluto artificial convergen, y se cae en el absurdo: la reducción de la maternidad a la pura biología, eliminando el componente simbólico, sacro, cultural, religioso, que es lo que hace que sea humana, permite reducirla tranquilamente a puro artificio de laboratorio (Roccella, 2015, 18 de febrero). 
Para Roccella, los derechos de las mujeres han sido eclipsados en los documentos internacionales por el aborto y la anticoncepción, y su efecto se ha dejado sentir sobre todo en países en vías de desarrollo.

Esta estrategia ha producido efectos paradójicos, como la afirmación de los derechos reproductivos en los países donde las mujeres no gozan de ninguna libertad. O donde (como en China y la India) el aborto sirve para eliminar a las niñas, favoreciendo el nacimiento del hijo varón. El método anticonceptivo más frecuente en el mundo es la esterilización femenina, al que han sido empujadas mujeres extremadamente pobres, para las que un pequeño incentivo era motivación suficiente para someterse a la operación. A menudo (véase la Conferencia de El Cairo de 1994 y luego en Pekín en 1995) se utilizó el feminismo como cobertura ideológica de las políticas neomalthusianas, con las que se ha podido financiar y poner en marcha grandes programas de control de la natalidad, especialmente en países del Tercer Mundo (Roccella, 2015, 18 de febrero).

La filósofa americana Christina Hoff Sommers coloca precisamente en ese Tercer Mundo el futuro del feminismo, y no precisamente trasladando conceptos occidentales sofisticados y ajenos a sus culturas sino luchando por algo tan básico como la libertad:

Soy una defensora apasionada de ese estilo de feminismo, que denomino feminismo de la igualdad. El feminismo de la igualdad no es nuevo: tiene sus raíces en la tradición política del liberalismo clásico que surgió en la llustración europea. (...).

Pero en general, las mayores batallas pendientes del feminismo de la igualdad en el siglo XXI no están aquí, sino en países donde las mujeres están siendo realmente oprimidas. Hay muchos lugares del mundo, especialmente en Oriente Medio y África, donde las mujeres no han conocido aún una brisa de libertad, mucho menos dos grandes olas de liberación. Creo que la liberación de la mujer en los países en vías de desarrollo será la principal lucha por los derechos humanos en nuestro tiempo" (Hoff Sommers, 2008).

\section{CONCLUSIONES}

El feminismo está aún lejos de las puertas del paraíso. En su versión radical no ha logrado dar respuesta a muchas de las necesidades y aspiraciones de las mujeres de Occidente y menos a las de países en vías de desarrollo. Vivimos en un mundo globalizado y en una sociedad multicultural. Muchas fronteras espaciales se han desvanecido o tienen coladeros por los que pasan seres que malviven en sus países y buscan un futuro mejor.
Las fronteras temporales también se desvanecen. Para Occidente parte de Oriente vive en la Edad Media y para esa parte de Oriente, Occidente ha perdido las coordenadas en su loca carrera hacia delante, que considera una panacea el derecho el aborto, el divorcio, la fecundación in vitro o la eutanasia. La sociedad occidental exporta su ideología, la oriental reacciona atrincherándose en el radicalismo y golpeando furiosamente contra él. Y la cuestión religiosa, la dignidad de la persona y en especial de la mujer, el valor de la familia están en juego en la batalla.

Pensar que todo progreso es bueno por ser progreso resulta infantil. El Medio Oriente precisa una seria revisión y adecuación de su ley a los derechos humanos adquiridos en la evolución de las civilizaciones. Quienes buscan asilo en países occidentales han de ajustarse a las leyes vigentes en esos países; pero Occidente también tiene muchas tareas pendientes en materia de derechos humanos y ha de entender que la práctica del positivismo jurídico a ultranza y la reducción obsesiva de los derechos a la materia reproductiva alejan la ley de la dignidad de la persona.

Si queremos vivir en un mundo globalizado hay que anclar fuertemente los cimientos: llegar a un sustrato común en materia de derechos humanos. En ese sentido, el diálogo que propone esta cuarta ola entre diversos feminismos es positivo, pero el riesgo de distraerse con los espejuelos de la fragmentación y la pluralidad, de la "micro-revolución" que construya una "nueva gramática" -como la denomina Beatriz Preciado- que desestabilice los modos de hacer y de mirar, siempre acecha y solo contribuiría a aumentar la confusión y alejarse de las necesidades reales de las mujeres del siglo XXI:

Hay, pues, mucho de valioso, responsable e incluso heroico en el feminismo contemporáneo. Pero si el movimiento en su conjunto quiere seguir siendo relevante y eficaz en la lucha contra la crueldad y la injusticia sexista, va a tener que cambiar. Tendrá que moderar su retórica contra los hombres, ser cuidadoso con la verdad y la exactitud. Finalmente, y tal vez más importante, debe convertirse en un movimiento inclusivo: tiene que ofrecer un lugar en su mesa a las mujeres conservadoras o moderadas. Unos pequeños grupos de feministas de izquierdas no van a conseguir derrotar el tráfico sexual, la mutilación genital femenina, las violaciones masivas en tiempos de guerra o las lapidaciones. La historia recordará su fracaso. Pero ¿qué ocurriría si Equality Now siguiera el ejemplo de Stanton y Anthony (lideres sufragistas de la primera ola) y formara una alianza con mujeres moderadas y conservadoras, y aun con las creyentes tradicionales? (Hoff Sommers, 2008). 
Eugenia Roccella pone sus esperanzas en la potencialidad natural de la mujer:

La utopía femenina no prefigura un mundo feliz de modelos abstractos, sino que trata de crear las condiciones para que la felicidad y el bienestar puedan nacer y desarrollarse; se mueve entre necesidades reales de las personas reales en situaciones reales, dentro de un sistema de relaciones.

Cada mujer, incluso cuando desempeña un papel público, o se compromete en un trabajo fuera del hogar, con una vocación o una ambición que debe mantener, conserva el amor por este espacio privado, que, sin embargo, tiene un valor universal. ¿Qué pasaría si la utopía minimalista y no violenta de las mujeres fuera derrotada, la competencia materna aniquilada, y realmente construyéramos un futuro deshumanizado?

La fuerza de las mujeres de hoy puede expresarse en la resistencia del sentido común contra el lugar común, en la confianza en la propia experiencia, en la capacidad para defender la humanidad propia y ajena, alimentando la esperanza" (Roccella, 2015, 18 de febrero).

"Quizá la madre naturaleza no obedece las reglas de la corrección política", -como dice Christina Hoff Sommers-. Del mismo modo que la pervivencia del ecosistema depende de un conocimiento y uso racional de los recursos naturales, el correcto equilibrio hombremujer, su desarrollo en armonía y plenitud y el futuro de la sociedad dependen del diálogo entre el progreso y el respeto a lo natural.

\section{BIBLIOGRAFÍA}

Abundancia, R. (2014, 8 de mayo). ¿Por qué en Finlandia querrías ser madre? SModa. El País. [En línea]. Disponible en http://smoda.elpais.com/moda/porque-en-finlandia-querrias-ser-madre/

Alonso-Gutiérrez, A. (2007, 21 de febrero). Triunfadoras que rompen filas. Aceprensa. [En línea]. Disponible en https:// www.aceprensa.com/articles/triunfadoras-que-rompen-filas/

Alstin, Z. (2010, 5 de octubre). Defending children against eroticised adult culture. Mercatornet. [En línea]. Disponible en http://www.mercatornet.com/articles/view/defending_children_against_ eroticised_adult_culture/

Badinter, E. (2004). Por mal camino. Madrid: Alianza.

Blázquez, S. (2015, 27 de abril). Rompiendo moldes. El País. [En línea]. Disponible en http://economia.elpais. com/economia/2015/04/27/actualidad/1430147490_184595.html

Givhan, R. (2015, 8 de junio). How can you be a fashion icon, says Carolina Herrera, if you're not wearing clothes? Washington Post. Disponible en http://www. washingtonpost.com/blogs/style-blog/ wp/2015/06/08/how-can-you-be-afashion-icon-says-carolina-herrera-ifyoure-not-wearing-clothes/).

Herman, E. (2008). El principio de Eva. Barcelona: Ediciones B.

Hoff Sommers, C. (2008, 19 de noviembre). What's Wrong and What's Right with
Contemporary Feminism? American Enterprise Institute. [En línea]. Disponible en https://www.aei.org/publication/ whats-wrong-and-whats-right-withcontemporary-feminism/

Hoff Sommers, C. (2013, 20 de agosto). School has become too hostile to boys. Time. [En línea]. Disponible en http://ideas.time.com/2013/08/19/ school-has-become-too-hostile-toboys/?iid=op-main-mostpop1

Infante, E. (2015, 30 de enero). Judit Mascó: "Si me lo hubiesen puesto más fácil podría haber sido chica Bond". Vanity Fair. [En línea]. Disponible en http:// www.revistavanityfair.es/celebrities/ articulos/judit-masco-entrevista-hubiera-sido-chica-bond-moda-evento-licor-43/20273

Kuebler, D. (2013, 30 de octubre). Survey Says: Women Are for Life. Public Discourse. [En línea]. Disponible en http://www.thepublicdiscourse. com/2013/10/11084/

Michelson, C. (2015, 16 de julio). La esclavitud de follar. The Clinic. [En línea]. Disponible en http://www.theclinic. cl/2014/02/11/la-esclavitud-de-follar/

Precht, A. (2008, 19 de marzo). Beatriz Preciado: "No se trata de decir que hemos superado el feminismo". [En línea]. Disponible en http://angelita.action.at/ beatriz-preciado-no-se-trata-de-decirque hemos-superado-el-feminismo/

Rocella, E., (2015, 18 de febrero). La mujer y la tecnomaternidad. Aceprensa.
[En línea]. Disponible en https://www. aceprensa.com/articles/la-mujer-y-latecnomaternidad/

Ruiz Zamora, M. (2010, 1 de marzo). "Feminismos". El País. [En línea]. Disponible en http://elpais.com/diario/2010/03/01/ opinion/1267398005_850215.html

Sullerot, E. (2014). Lettre d'une enfant de la guerre aux enfants de la crise. Paris: Fayard.

Vicente, A. (2015, 18 de agosto). Elisabeth Badinter: "La mujer no arreglará lo que ha hecho mal el hombre". El País. [En línea]. Disponible en http://internacional. elpais.com/internacional/2015/08/05/ actualidad/1438790334_204242.html

Walter, N. (2010). Muñecas vivientes. Madrid: Turner.

Weiss, B. (2013, 28 de diciembre). Camille Paglia: "A Feminist Defense of Masculine Virtues". The Wall Street Journal. [En línea]. Disponible en http://www. wsj.com/news/articles/SB1000142405 2702303997604579240022857012920

Yanke, R. (2015, 8 de marzo). Feminismo 3.0, la nueva ola. El Mundo. [En línea]. Disponible en http://www.elmundo.es/espana/2015/ 03/08/54fb4b6be2704ec7518b4570.html

\section{Recursos web}

Entrevista a Valeria Mazza: "Estoy contenta con lo que soy". [En línea]. Disponible en http://www.terra.com/mujer/articulo/html/hof136641,2.htm 